\section{Profesor dr Miroslav \\ Demić, \\ dipl. inž. \\ Mašinski fakultet, \\ Kragujevac}

\section{MERENJE PARAMETARA KRETANJA VOZILA BEZ ŽIROSKOPSKI STABILISANIH PLATFORMI}

\author{
UDC: $629.3 .017 .3: 623.437 .4$
} $929.33: 531.383$

Rezime:

Prostorni položaj težišta vozila i rotacije karoserije značajni su za analizu dinamike, ponašanje na putu, oscilatornu udobnost vozila, bezbedno odvijanje saobraćaja $i$ sl. Pomenuti parametri se u fazi projektovanja vozila određuju metodama dinamičke simulacije, a kod izvedenih vozila merenjima u stvarnim eksploatacionim uslovima. Problem koji je u ovom radu razmotren odnosi se na praktična merenja parametara kretanja vozila. Naime, translatorne koordinate težišta vozila se, uobičajeno, utvrđuju na osnovu registrovanih linearnih ubrzanja težišta vozila (koja se kasnije, jednom ili dva puta, integrale radi izračunavanja brzine ili pomeranja), a uglovi rotacije karoserije se, najčešće, mere žiroskopski stabilisanim platformama. Problem koji se pri tome javlja je cena pomenutih platformi (do sto hiljada evra), pa je retko koja institucija njima opremljena. U ovom radu nastojano je da se utvrde parametri kretanja vozila na osnovu šest registrovanih linearnih ubrzanja karakterističnih tačaka vozila.

Ključne reči: motorno vozilo, parametri kretanja vozila, položaj težišta vozila, merenje parametara kretanja vozila.

\title{
MEASUREMENT OF VEHICLE PARAMETERS OF MOTION WITHOUT GYRO-STABILIZED PLATFORMS
}

Summary:

Spatial position of vehicle C.G. as well as angular parameters of body rotation are of major importance for analysis of vehicle dynamics, handling, vibrational comfort, safe service in traffic etc. The mentioned parameters are determined by use of methods of dynamic simulation in phase of development, and by means of test measurement for vehicles in real service conditions. The problem that is to be taken into consideration here is related to practical measurement of vehicle motion parameters. Translational coordinates of vehicle C.G. are usually measured on the basis of registered linear accelerations of vehicle C.G. (once or twice integrated later, for calculation of displacement or velocity) and body angles are usually measured on gyroscope-stabilized platforms. The problem which occurs in these cases is the platform price (up to 100.000 EUR), not easily affordable for researchers. This paper attempts to determine vehicle motion parameters on the ground of six registered linear accelerations of specific body spots.

Key words: vehicle, vehicle motion parameters, position of vehicle C.G., measurement of vehicle motion parameters.

\section{Uvod}

Tokom kretanja vozilo menja prostorni položaj $\mathrm{u}$ odnosu na proizvoljno odabrani nepokretni koordinatni sistem (često nazvan: inercijalni, globalni) [23, 24]. Za analizu parametara kretanja vozila neophodno je poznavati veličine pomeranja, brzine ili ubrzanja njegovih karakterističnih tačaka [5, 6, 9-17, 21, 22, 26]. Ra- 
di uprošćenja, vozilo se, najčešće, posmatra kao kruto telo koje vrši opšti slučaj prostornog kretanja. Za opisivanje takve vrste kretanja neophodno je poznavati 6 generalisanih koordinata: tri translacije $\mathrm{i}$ tri rotacije [24], što je uprošćeno prikazano na slici 1 . Pri tome je najjednostavnije da se posmatraju translatorna kretanja centra mase (tačka $\mathrm{C}$ na slici) koja su definisana koordinatama $\mathrm{X}_{\mathrm{C}}, \mathrm{Y}_{\mathrm{C}}$ i $\mathrm{Z}_{\mathrm{C}} \mathrm{u}$ odnosu na nepokretni koordinatni sistem CXYZ i tri rotacije oko osa pokretnog koordinatnog sistema (čvrsto vezanog za vozilo Cxyz) [24]. Kod vozila su pomenuti uglovi poznati pod nazivima: valjanje (oko podužne), galopiranje (oko poprečne) i vijuganje (oko vertikalne ose).

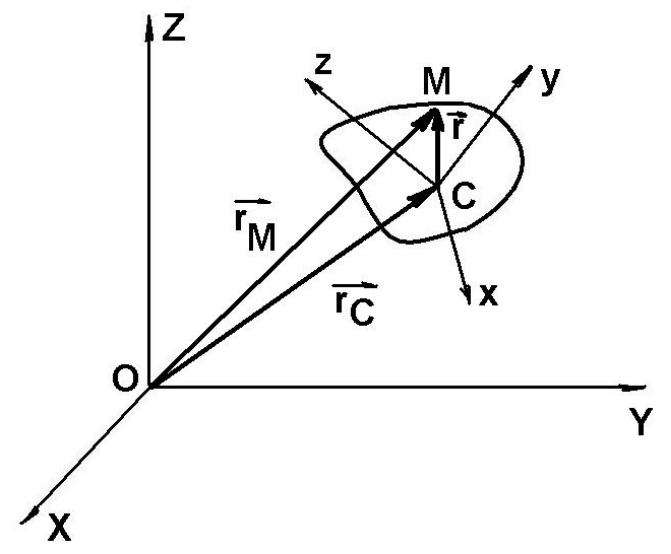

Sl. 1 - Koordinatni sistemi za definisanje prostornog položaja krutog tela

Prostorni položaj težišta vozila i rotacije karoserije značajni su za analizu dinamike, ponašanje na putu, oscilatornu udobnost vozila, bezbedno odvijanje saobraćaja i sl., a parametri kretanja se u fazi projektovanja vozila izračunavaju metodama dinamičke simulacije, a kod izvedenih vozila merenjima $u$ stvarnim eksploatacionim uslovima.
U ovom radu biće reči o mogućnostima za merenje parametara kretanja vozila. Translatorna kretanja težišta vozila u praksi se utvrđuju na osnovu registrovanih ubrzanja koja se dva puta integrale, dok se ugaona pomeranja registruju uređajima koji koriste žiroskope. Treba naglasiti da je osnovni nedostatak žiroskopskih uređaja njihova izuzetno visoka cena, koja dostiže i 100000 evra [25], pa i najbogatije ustanove retko njima raspolažu. Zbog toga je bilo opravdano razviti postupak merenja parametara kretanja vozila bez korišćenja žiroskopa.

\section{Prikaz metode}

Radi lakšeg opisa razvijene metode merenja, u najkraćim crtama biće dat osvrt na najosnovnije pojmove iz kinematike opšteg kretanja krutog tela [24].

Prema slici 1, vektor položaja proizvoljno izabrane tačke $M$ na krutom telu koje obavlja opšti slučaj prostornog kretanja dat je izrazom:

$\vec{r}_{M}=\vec{r}_{C}+\vec{r}$

pri čemu je rastojanje tačke $M$ od tačke C konstantno.

Brzine i ubrzanja tačke $M$ mogu se izračunati jednostrukim ili dvostrukim diferenciranjem vektorske jednačine (1) po vremenu, ali kako je ova teorija poznata iz [24], o tome neće biti reči.

Parametri kretanja krutog tela, prikazanog na slici 1, mogu se izračunati i primenom matričnog računa [24]. U tom slučaju moraju se poznavati matrice transformacija između koordinatnih sistema OXYZ i Cxyz. Kako je i ova teorija poznata, a imajući u vidu činjenicu da transformacija ko- 
ordinata predstavlja komplikovan posao, koji se se može lako rešiti primenom programskog paketa Mathematica [27], u ovom radu je ocenjeno celishodnim da se za izračunavanje parametara kretanja $u$ opštim brojevima koristi programski paket NEWEUL [23], koji je namenjen za analizu dinamike sistema krutih tela.

U daljem tekstu će biti više reči o razvijenom postupku za merenje parametara kretanja vozila bez korišćenja žiroskopskih uređaja, čija je ideja prikazana na slici 2. Imajući u vidu pravila NEWEUL-a, za opisivanje kretanja proizvoljno izabrane tačke uvedena su četiri koordinatna sistema (globalni-inercijalni, koji je istovremeno i referentni koordinatni sistem OXYZ, pokretni koordinatni sistem koji je čvrsto vezan za telo vozila Cxyz i koordinatni sistem sa početkom u posmatranoj tački, a čije su ose paralelne osama pokretnog koordinatnog sistema, jer su čvrsto vezane za telo vozila).

Parametri kretanja posmatrane tačke izračunavaju se u odnosu na globalni koordinatni sistem OXYZ, ali se mogu, automatski, primenom pomenutog programa, projektovati na bilo koji, pa i pokretni koordinatni sistem Cxyz. Ova činjenica je od velikog značaja za razvoj metode, o čemu će u daljem tekstu biti više reči.

Kao što je napomenuto, cilj rada je da se utvrđivanje parametara kretanja vozila vrši bez korišćenja žiroskopski stabilisanih platformi. Kako prostorni položaj potpuno opisuju šest generalisanih koordinata, očigledno je da se njihove vrednosti mogu izračunati na osnovu šest poznatih pomeranja, brzina ili ubrzanja bilo kojih tačaka krutog tela, a u praksi je najjednostavnije izmeriti šest projekcija ubrzanja tih tačaka.

Izbor broja i položaja mernih tačaka može biti proizvoljan, ali je najjednostavnije da se izaberu dve karakteristične tačke na specijalno urađenoj krutoj ramnoj konstrukciji, koje ćemo označiti sa 1 i 2 . Ubrzanja tih tačaka mere se u tri pravca (slika 2), sa koordinatama u odnosu na pokretni koordinatni sistem Cxyz $\left\{\mathrm{a}_{1}, \mathrm{~b}_{1}, \mathrm{c}_{1}\right\}$, odnosno $\left\{-\mathrm{a}_{2}\right.$, $\left.-b_{2},-c_{2}\right\}$. Radi lakše analize, poželjno je da su tačke simetrične u odnosu na tačku C (pogled „П“ na slici 2). Pri tome, veličine a, b i c se mogu proizvoljno izabrati,

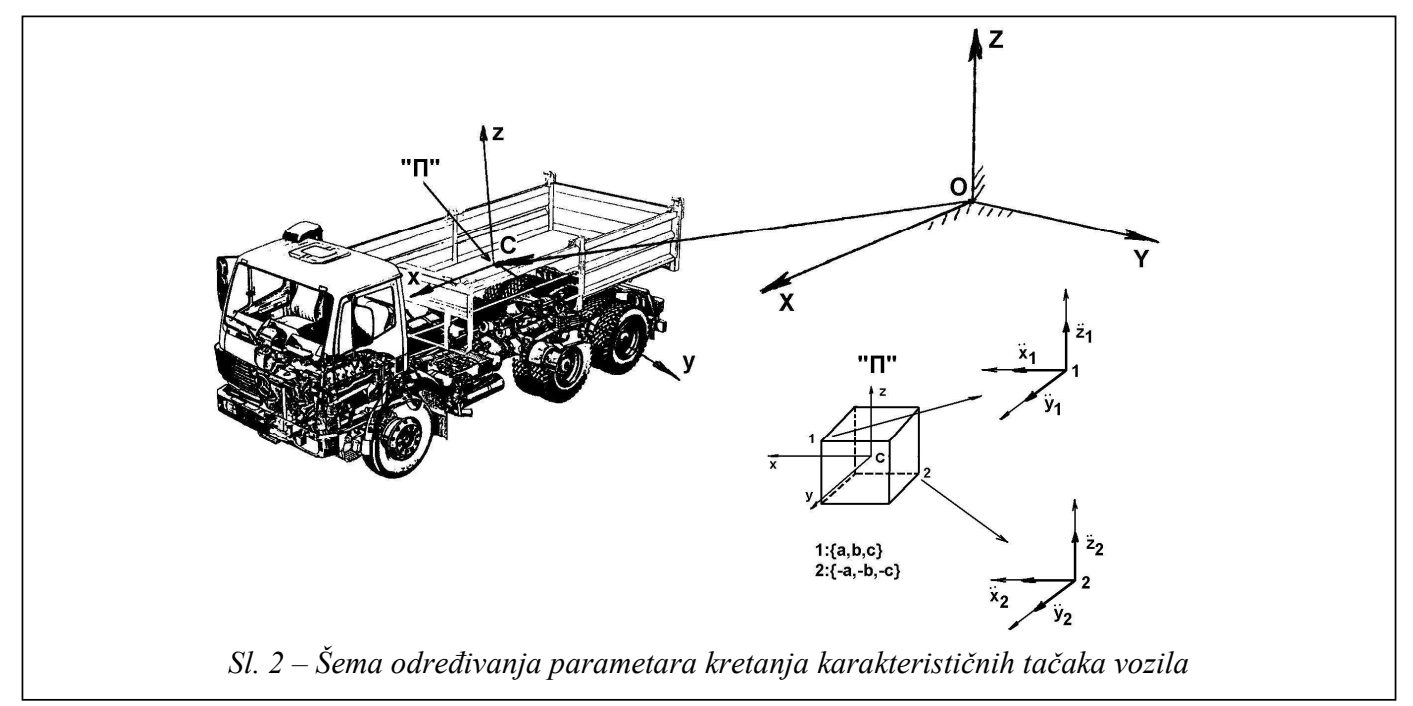


ali je povoljnije da budu što veće. Komponente registrovanih ubrzanja prikazane su na istoj slici.

Ubrzanja se registruju induktivnim ili piezoelektričnim davačima ubrzanja, koji imaju svoje prednosti i nedostatke, a detaljno su opisani u $[18,20]$. Ističemo da induktivni davači imaju jednostavnu mogućnost kalibracije. Njihova donja učestanost jednaka je nuli, ali je nedostatak što su osetljivi i na ubrzanja koja im se ne saopštavaju samo u pravcu ose merenja i što imaju relativno nisku gornju graničnu učestanost. Piezoelektrični davači su manje osetljivi na uticaj drugih komponenata ubrzanja, komplikovanija je kalibracija, donja učestanost im nije jednaka nuli, ali su manje osetljivi na udare, i posebno su pogodni za korišćenje kao troosni $[18,20]$. Kako su davači ubrzanja postavljeni na kruti okvir koji je čvrsto vezan za telo vozila, oni registruju ubrzanja u pravcu osa pokretnog koordinatnog sistema, što je značajno za dalju analizu. U praksi se pomeranja posmatranih tačaka dobijaju dvostrukim integraljenjem registrovanih ubrzanja.

Primenom NEWEUL-a, dobijene su komponente pomeranja tačaka 1 i 2 u pravcu osa pokretnog koordinatnog sistema:

$x_{1,2}=X_{C} \cos \psi \cos \theta+Y_{C} \sin \theta \sin \varphi \cos \psi+$ $Y_{C} \sin \psi \cos \varphi-Z_{C} \sin \theta \cos \varphi \cos \psi+$

$+Z_{C} \sin \psi \sin \varphi \pm a_{1,2}$

$y_{1,2}=-X_{C} \sin \psi \cos \theta-Y_{C} \sin \psi \sin \theta \sin \varphi+$

$+Y_{C} \cos \psi \cos \varphi+Z_{C} \sin \psi \sin \theta \cos \varphi+$

$+Z_{C} \sin \varphi \cos \psi \pm b_{1,2}$

$z_{1,2}=X_{C} \sin \theta-Y_{C} \sin \varphi \cos \theta+$

$+Z_{C} \cos \theta \cos \varphi \pm c_{1,2}$ gde su:

$X_{C}, Y_{C}, Z_{C}$ - nepoznate vrednosti koordinata težišta vozila u odnosu na nepokretni koordinatni sistem,

- nepoznate vrednosti uglova valjanja, galopiranja i vijuganja vozila u odnosu na pokretni koordinatni sistem,

$a_{1,2}, b_{1,2}, c_{1,2}$ - koordinate mernih tačaka 1 i 2 u odnosu na pokretni koordinatni sistem, a

$\mathrm{x}_{1,2}, \mathrm{y}_{1,2}, \mathrm{z}_{1,2}$ - poznate veličine pomeranja tačaka 1 i 2 u pravcu osa pokretnog koordinatnog sistema, dobijene dvostrukim integraljenjem registrovanih ubrzanja.

Kao što je rečeno, komponente ubrzanja posmatranih tačaka u pravcu pojedinih osa registruju se odgovarajućim davačima, čije su izlazne veličine električni naponi. Pri tome, između tih veličina, u preporučenoj oblasti učestanosti primene davača ubrzanja, postoje relacije:

$a_{x, y, z}=k_{x, y, z} u_{x, y, z}$

gde su:

$a_{x, y, z}-$ komponente ubrzanja $u$ pravcu osa $\mathrm{x}, \mathrm{y}, \mathrm{z}$,

$\mathrm{u}_{\mathrm{x}, \mathrm{y}, \mathrm{z}}$ - registrovani naponi srazmerni komponentama ubrzanja u pravcu osa $\mathrm{x}, \mathrm{y}$, z (kako su izlazni naponi obično mali, neophodno ih je pojačati odgovarajućim pajačavačima, pa se naponi mere na izlazu tih uređaja [18]), a

$\mathrm{k}_{\mathrm{x}, \mathrm{y}, z}$ - koeficijenti srazmere, za ceo merni lanac, od davača do sistema za memorisanje podataka.

Kao što je rečeno, pomeranja tačaka 1 i 2 mogu se izračunati dvostrukim integraljenjem ubrzanja, tj.: 


$$
\begin{aligned}
& x_{1,2}=k_{x} \iint a_{x} d t \\
& y_{1,2}=k_{y} \iint a_{y} d t \\
& z_{1,2}=k_{z} \iint a_{z} d t
\end{aligned}
$$

Analizom izraza (2) može se utvrditi da on sadrži šest jednačina sa šest nepoznatih $\left(\mathrm{X}_{\mathrm{C}}, \mathrm{Y}_{\mathrm{C}}, \mathrm{Z}_{\mathrm{C}}, \varphi, \theta, \psi\right)$ i šest poznatih veličina pomeranja $u$ pravcu osa pokretnog koordinatnog sistema $\left(\mathrm{x}_{1}, \mathrm{x}_{2}\right.$, $\left.\mathrm{y}_{1}, \mathrm{y}_{2}, \mathrm{z}_{1}, \mathrm{z}_{2}\right)$. Koordinate tačaka 1 i 2 $\mathrm{a}_{1,2}, \mathrm{~b}_{1,2}$ i $\mathrm{c}_{1,2}$ su poznate, pa je moguće izračunati parametre kretanja vozila na osnovu poznatih komponenti kretanja tačaka 1 i 2 mernog sistema.

Jednačine (2) su transcedentne, spregnute i nelinearne. Mogu se uprostiti linearizacijom u slučaju malih uglova rotacija, ali imajući u vidu da ugao vijuganja vozila nije u eksploataciji mali, taj prilaz se ne može primeniti. Zbog toga sistem jednačina mora biti rešen numerički. $U$ te svrhe je u početnom stadijumu istraživanja korišćena metoda linearnih iteracija, ali, zbog loše konvergencije rešenja, nije dala zadovoljavajuće rezultate, pa je usvojen postupak zasnovan na optimizaciji, uz korišćenje metode Hooke-Jeevesa [4-6, 9-13]. Pri tome je minimiziran kvadrat grešaka između izračunatih vrednosti pomeranja tačaka 1 i 2 datih izrazom (2) i izmerenih veličina pomeranja datih izrazom (4). Preciznije rečeno, funkcija cilja bila je oblika:

$$
\begin{aligned}
\Phi & =\left(x_{1 r}-x_{1 i z m}\right)^{2}+\left(x_{2 r}-x_{2 i z m}\right)^{2}+ \\
& +\left(y_{1 r}-y_{1 i z m}\right)^{2}+\left(y_{2 r}-y_{2 i z m}\right)^{2}+ \\
& +\left(z_{1 r}-z_{1 i z m}\right)^{2}+\left(z_{2 r}-z_{2 i z m}\right)^{2}
\end{aligned}
$$

gde indeksi r i izm pokazuju da se radi o računskim i izmerenim vrednostima odgovarajućih komponenti pomeranja. Mi- nimizacija vrednosti izraza (5) vršena je za svaku diskretnu vrednost izračunatih komponenti pomeranja (1-N), uz ograničenja datih izrazom:

$$
\begin{aligned}
& -\pi / 2<=\varphi<=\pi / 2 \\
& -\pi / 2<=\theta<=\pi / 2 \\
& -\pi<=\psi<=\pi
\end{aligned}
$$

Blok-dijagram postupka zasnovanog na metodi optimizacije prikazan je na slici 3, na kojoj je očigledno da se u svakoj tački za koju su poznati podaci o šest izmerenih pomeranja vrši izračunavanje šest nepoznatih parametara kretanja vozila. Završetak iterativnog procesa, za svaku tačku, realizovan je kada je razlika dve susedne vrednosti funkcije cilja bila manja od $10^{-20}$. U fazi optimizacije korišćen je metod spoljašnjih kaznenih funkcija, koji je detaljno opisan u [4-6, 9-13], pa o tome neće biti reči. Sva izračunavanja vršena su uz pomoć specijalno razijenog programskog paketa u paskalu.

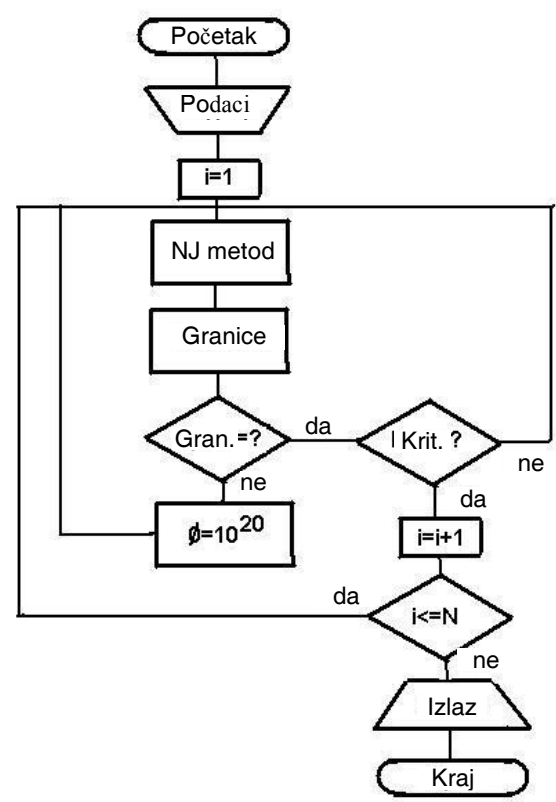

Sl. 3 - Blok-dijagram razvijenog postupka za izračunavanje parametara kretanja vozila 


\section{Testiranje metode}

U nedostatku eksperimentalnih podataka, za testiranje razvijene metode korišćene su vremenske serije zasnovane na slučajnim brojevima ravnomerno raspoređenim $u$ oblasti $\{0,1\}$. Korišćene vremenske serije imale su 4096 tačaka i korak od 0,001 s, čime je obezbeđena pouzdanost u oblasti učestanosti 0,25-500 Hz [1] (ilustrativni primer za valjanje prikazuje slika 4).

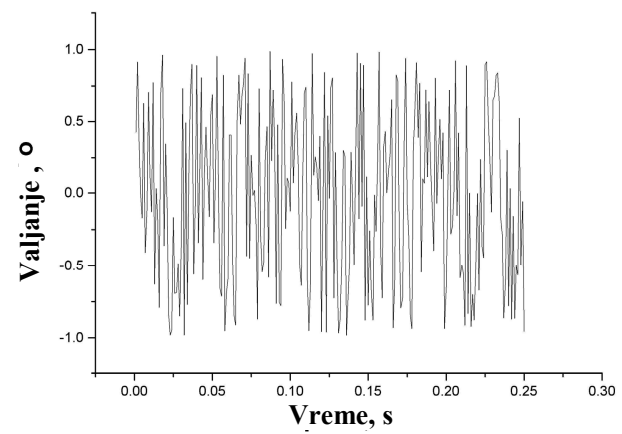

Sl. 4 - Ilustracija vremenske serije valjanja karoserije

Sa slike je očigledno da je test veoma rigorozan, jer je promena simuliranih eksperimentalnih podataka veoma oštra, pa je za ocenu razvijenog postupka neophodno koristiti statističke metode. Treba naglasiti da su i analize sa većim brojem tačaka (i nižom donjom pouzdanom učestanošću) pokazale

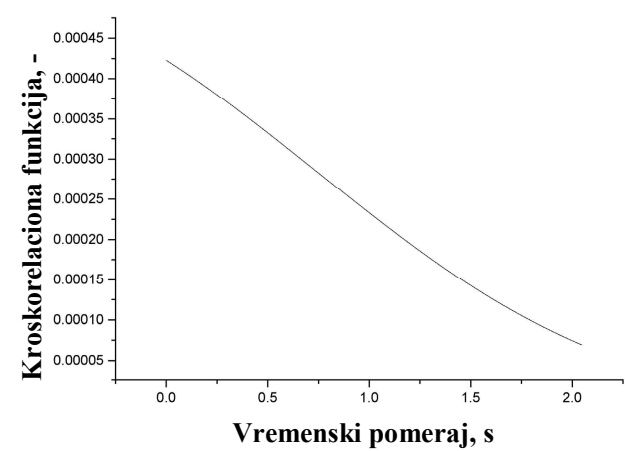

Sl. 5 - Funkcija kroskorelacije test i izračunatog valjanja vozila isti trend ponašanja metode, što je značajno za njeno korišćenje u eksploataciji vozila, kada su i niske učestanosti veoma značajne.

U prvoj fazi testiranja, izračunate su funkcije kroskorelacije [1-4], uz korišćenje programa ANALSIGDEM [7], a ilustrativni primer prikazan je na slici 5.

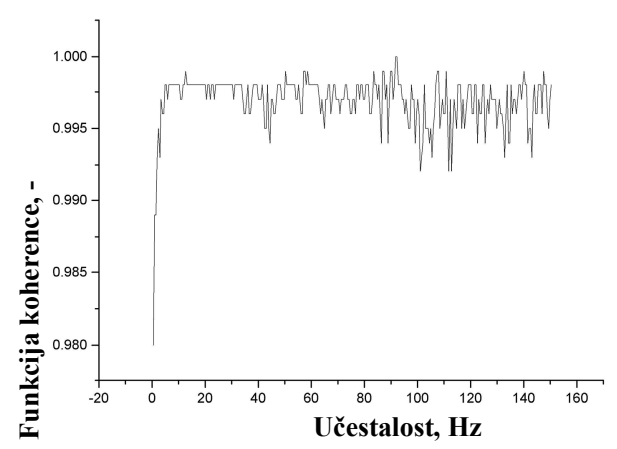

Sl. 6 - Funkcija koherenci translatornog kretanja vozila (x pravac)

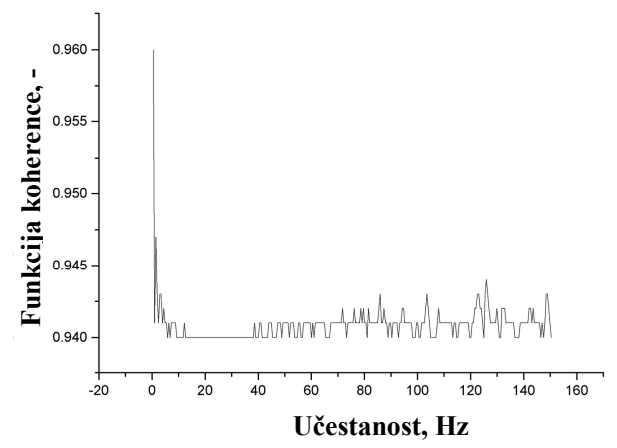

Sl. 7 - Funkcija koherenci translatornog kretanja vozila (y pravac)

Analizom kroskorelacionih funkcija izmerenih i izračunatih veličina utvrđeno je da postoji trend njihovog opadanja sa porastom vremena, što pokazuje da se zavisnost posmatranog para veličina može smatrati stacionarnim, tj. ne postoji porast njihovih razlika sa porastom vremena.

Imajući u vidu karakter usvojenih test vremenskih realizacija, ocenjuje se celishodnim da se izračunaju i funkcije kohe- 
renci izmerenih i izračunatih veličina, uz korišćenje programa „DEMPARKOH“ [8], a koje su prikazane na slikama 6-11.

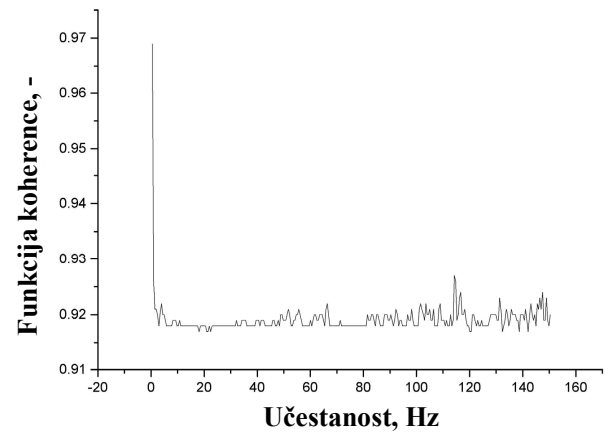

Sl. 8 - Funkcija koherenci translatornog kretanja vozila (z pravac)

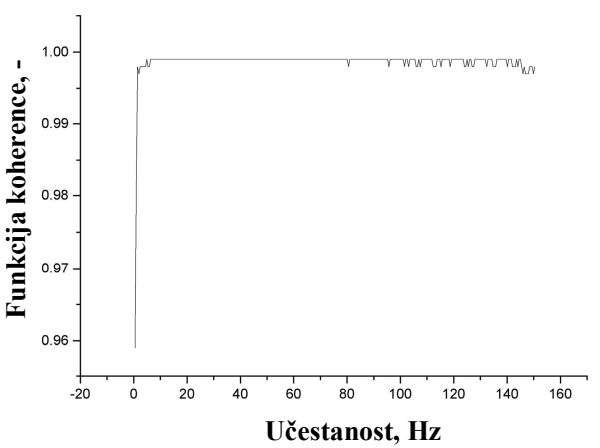

Sl. 9 - Funkcija koherenci rotacionog kretanja vozila (valjanje)

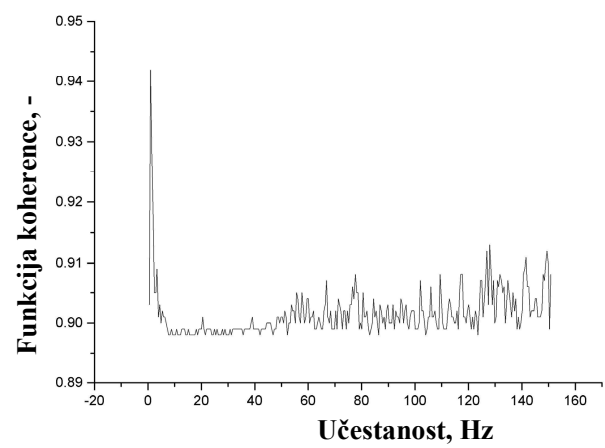

Sl. 10 - Funkcija koherenci rotacionog kretanja vozila (galopiranje)
Analizom podataka sa slika 6-11 može se utvrditi da funkcije koherenci, izračunate sa 1024 usrednjavanja, imaju veoma visoku vrednost (iznad 0,9), što pokazuje da izmerene i izračunate vrednosti pomeranja tačaka 1 i 2 imaju veoma sličan frekventni sadržaj. Ovaj stav potvrđuje visoku pouzdanost razvijene metode za određivanje parametara kretanja vozila.

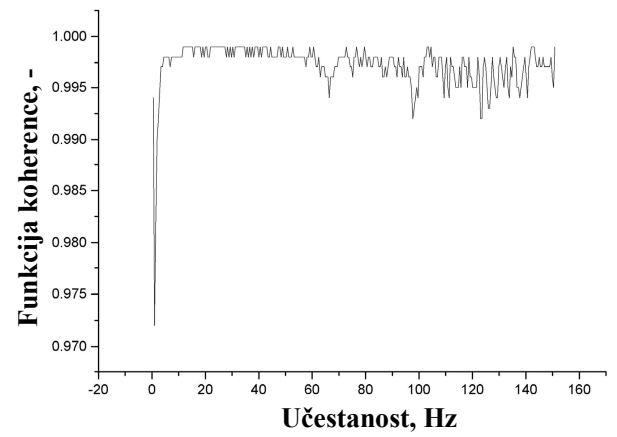

Sl. 11 - Funkcija koherenci rotacionog kretanja vozila (vijuganje)

\section{Zaključak}

Razvijena metoda omogućava posredno izračunavanje šest parametara kretanja vozila (tri translacije i tri rotacije). Testovi zasnovani na dinamičkoj simulaciji, uz korišćenje vremenskih serija slučajnog karaktera, pokazali su veliku pouzdanost izračunatih vrednosti parametara kretanja vozila, pa se razvijeni postupak može koristiti za eksperimentalna utvrđivanja parametara kretanja vozila bez žiroskopski stabilisanih platformi.

Literatura:

[1] Bendat, J. S., Piersol A. G.: Random Data Analysis and Measurement Procedures, John Wiley and Sons, London, 2000.

[2] Bendat, J. S.: Nonlinear Systems-Techniques and Applications, John Wiley and Sons, London, 1998. 
[3] Bendat, J. S., Piersol, A. G.: Engineering Applications of Correlation and Spectral Analysis, John Wiley and Sons, London, 1980.

[4] Bunday, P.: Basic Optimization Methods, Spottiswoode Ballantyne, Colchester and London, 1984.

[5] Demić, M.: Identification of Vibration parameters for Motor Vehicles, Vehicle System Dynamics, Vol. 27, 1997, pp. 65-88.

[6] Demić, M.: Optimization of Characteristics of Elasto-Damping Elements from Aspect of Oscillatory Comfort and Vehicle Handling, Int. J. of Vehicle Design, Vol. 17, № 1 , 1996, pp. 76-91.

[7] Demić, M.: ANALSIGDEM - Software for signal analysis, www.ptt.yu/korisnici/i/m/imizm034/, 2003.

[8] Demić, M.: DEMPARCOH: Software for partial coherence function calculation, www.ptt.yu/korisnici/i/m/imizm034/, 2003.

[9] Demic, M.: Optimization of Vehicles Elasto-Damping Elements Characteristics From the Aspect of Ride Comfort, Vehicle System Dynamics, Vol. 23 (1994).

[10] Demić, M.: A contribution to optimization of vehicle seats, Int. J. of Vehicle Design, 5/6, 1991, 10 pp. 618-629.

[11] Demić, M.: A contribution to the optimization of the characteristics of elasto-damping elements of passenger cars, Vehicle System Dynamics, Vol. 19, 1990, pp. 3-18.

[12] Demić, M.: Analysis of Influence of Design Parameters on Steered Wheels Shimmy oh Heavy Vehicles, Vehicle System Dynamics, Vol. 26, 1996, pp. 343-379.

[13] Demić, M.: Optimizacija oscilatornih parametara motornih vozila, Monografija, Mašinski fakultet u Kragujevcu, 1997.
[14] Ellis, J. R.: Vehicle Handling Dynamics, Mechanical engineering Publications Limited, London, 1994.

[15] Gillespie, T.: Fundamentals of Vehicle Dynamics, SAE, Warrendale, 1992

[16] Genta, A.: Motor Vehicle Dynamics, Politecnika di Torino, 2003.

[17] Georg, R.: Vehicle Dynamics, Lecture Notes, Fachhochschule Regensburg, 2004.

[18] Hottinger Balldwin Messtechnik, Elektrisches messen mechanischer groessen, 1980.

[19] Hačaturov, A. A. i dr.: Dinamika sistemi: doroga-šina-avtomobilj-voditelj, Mašinostrojenije, Moskva, 1976.

[20] Jovanović, S., Pijevčević, D.: Poređenje odziva piezoelektričnih $\mathrm{i}$ induktivnih davača ubrzanja na mehaničke udare i postprocesno dobijanje pomeranja, Vojnotehnički glasnik, 1/2006, str. 97-101.

[21] Miliken, W. F. Miliken, D. L.: Race Car Vehicle Dynamics, SAE, Warrendale, 1995.

[22] Mitschke, M.: Dynamik der Kraftfahrzeuge, Springer Verlag, 1972.

[23] NEWEUL: Software package for the dynamic analysis of mechanical systems, University of Stuttgart.

[24] Pars, L.: A Treatise on Analytic Dynamics, Heinemann, London, 1971.

[25] Regelungs und Messtecnik - Dynamik Test Systems, Hamburg, Germany, 2006.

[26] Simić, D.: Dinamika motornih vozila, Naučna knjiga, Beograd, 1988.

[27] Wolfram Research: Mathematica 5.2 